\title{
Intercambios gestuales: cuerpo y diversidad en el arte. Reflexiones desde el proceso de un laboratorio de creación en Colombia
}

\author{
Gestural exchanges: body and diversity. Reflections from the process \\ of a creation laboratory in Colombia
}

\author{
Melvy BOCANEGRA.Gimnasio Fontana.melvybocanegrac@gmail.com \\ Diana CASTILLO. Artista independiente. alkantarazul@hotmail.com \\ Marcela GARZÓN. Universidad Antonio Nariño. marcegarzong@gmail.com \\ Mónica ROMERO. Universidad Nacional de Colombia.mopomapa2@gmail.com \\ Autoría colectiva: Colectivo Otro: intercambiosgestuales@gmail.com
}

Resumen: El colectivo Otro es un colectivo de artistas que hemos participado en el Programa Nacional de Laboratorios de Creación en Artes visuales en Colombia ${ }^{1}$ durante siete años consecutivos. Estos son espacios educativos no formales para intercambiar saberes y experiencias en torno a las prácticas artísticas tanto académicas (provenientes de las universidades), como tradicionales y comunitarias. Nos hemos centrado más en estas últimas dado que el laboratorio que realizamos no se dirige únicamente a artistas sino a profesores de artes, docentes, gestores, trabajadores sociales, terapeutas, madres comunitarias, líderes sociales, cuidadores, personas con discapacidad y otros profesionales que trabajan con comunidades diversas.

Esto nos ha significado revisar constantemente la incidencia social, la responsabilidad en los procesos educativos, la capacidad de diálogo creativo y crítico con las distintas personas y sus contextos.

\footnotetext{
1. Desde un comienzo éstos se pensaron como un programa paralelo a los Salones Nacionales de Artistas, que es una de las plataformas de mayor tradición en Colombia para el reconocimiento de artistas plásticos y visuales. Más información: http:// www.mincultura.gov.co/areas/artes/artes-visuales/laboratorios-artes-visuales/Paginas/default.aspx y http://labsmincultura. entrelasartes.org/
} 
Las actividades realizadas generan proyectos de creación colaborativa, donde el trabajo colectivo es torna fundamental, así como la capacidad para investigar y crear alternativas que incidan en la transformación de las condiciones de exclusión vigentes. A través del cuerpo, tanto de facilitadoras como participantes (roles que se van intercalando), se vivencia la diversidad cuestionando imaginarios y discursos dominantes que hay alrededor de la misma.

Con esta experiencia concreta y sus reflexiones, esperamos aportar al debate entre educación artística y diversidad desde el cuerpo.

Palabras clave: Discapacidad, creación colaborativa, educación artística, experiencia, educación no formal.

Abstract: As an artists collective we have participate in the National Program of Visual Arts Creation Laboratories in Colombia ${ }^{2}$ for seven consecutive years. These are non-formal educational spaces spaces to exchange knowledge and experiences around both academic (from universities), traditional and community art practices. We focused more on the latter, since the laboratories we make do not address only artists but arts teachers, professors, promoters, social workers, therapists, community mothers, social leaders, caregivers, peoples with disability and other professionals working with diverse communities.

This has meant that we constantly review the social incidence responsibility in the educational process, the capability of creative and critical dialogue with different people and their contexts.

The activities generate collaborative creation projects, where collective work becomes vital, as well as the ability to research and create alternatives that affect the transformation of existing exclusion conditions. Through the body, both of facilitators and participants (roles that alternate), diversity is experienced by questioning imaginaries and dominant discourses around it.

It is from this particular experience and their reflections we expect to contribute to the debate between arts education and diversity from the body.

Keywords: Disability, collaborative creation, arts education, experience, nonformal education.

2. From the beginning they were intended as a parallel event to the National Artists Exhibit, which is one of the most traditional platforms in Colombia for the recognition of visual and fine artists. More information: http://www.mincultura. gov.co/areas/artes/artes-visuales/laboratorios-artes-visuales/Paginas/default.aspx and http://labsmincultura.entrelasartes.org 


\section{Experiencias artísticas desde la diversidad}

En la batalla del cuerpo contra el mundo, los sentidos sufren, y comenzamos a sentir muy poco lo que tocamos, a escuchar muy poco lo que oímos, a ver muy poco lo que miramos.

Escuchamos, sentimos y vemos según nuestra especialidad. Los cuerpos se adaptan al trabajo que deben realizar. Esta adaptación, a su vez, lleva a la atrofia y a la hipertrofia. Para que el cuerpo sea capaz de emitir y recibir todos los mensajes posibles, es preciso que recupere su armonía. (Augusto Boal, 2002, p.139)

El Laboratorio “Cuerpo y Diversidad en el Arte. Intercambios Gestuales" es un espacio significativo en Colombia que vincular el arte, la educación y la discapacidad. Se caracteriza por albergar en una misma experiencia a personas con diferencias marcadas en edades, habilidades, condiciones, formaciones y situaciones económicas y sociales. Nuestros grupos comprenden niños desde los 3 o 4 años hasta adultos mayores de 80 años, con y sin discapacidad, algunos no han acabado su primaria, otros tienen posgrados. Trabajamos con comunidades como forma de enriquecer a cada individuo, hacemos énfasis en la experiencia estética, promovemos las agrupaciones teniendo en cuenta lo individual y lo colectivo, la gestión comunitaria, la comprensión de las realidades particulares a partir de la diversidad y la multiplicidad del arte.

Las personas que participan en el Laboratorio fortalecen liderazgos locales que promueven experiencias con la discapacidad, mediadas por el arte, la reflexión, la sensibilidad, el reconocimiento y la valoración de movimientos sociales de cooperación, como los grupos familiares o las comunidades educativas. Desarrollamos un proceso dinámico y dialógico, múltiple, capaz de recoger los intereses, saberes y prácticas que dan cuenta de la diversidad del país. Nuestra apuesta es construir una comunidad más sensible capaz de valorar la diferencia como rasgo distintivo.

En la historia reciente de Colombia, hacia mediados del siglo XX, el país entra en un conflicto $\operatorname{armado}^{3}$ que recrudece la desigualdad social y la segregación, por lo que en 1991 se crea una nueva Constitución Nacional que consagra los derechos fundamentales de las personas, tiempo en el que paradójicamente se vive el mayor recrudecimiento de los distintos tipos de violencia (Chaparro-Amaya, 2005). Esto ha provocado la instalación del miedo y la exclusión como formas cotidianas de relacionarnos y una desconfianza hacia el proceso de paz que se adelanta actualmente en la Habana (Cuba).

\footnotetext{
3. Para ampliar la información, consultar: Centro Nacional de Memoria Histórica (2013). ;Basta ya! Colombia: memorias de guerra y dignidad. Informe general Grupo de Memoria Histórica. Recuperado de: http://www.centrodememoriahistorica. gov.co/descargas/informes2013/bastaYa/BYColombiaMemoriasGuerraDignidadAgosto2014.pdf
} 
El llamado que realiza el gobierno nacional es "entender la paz como una oportunidad, como una gran palanca de cambio para hacer lo que no hemos logrado hacer en cincuenta años de guerra" (Jaramillo, 2013, p.2). Esto significa que hay una posibilidad de encontrar mejores condiciones de vida para los colombianos, lo que requiere recuperar la confianza y vincular a la sociedad en el proceso de paz, promoviendo la cogestión, la participación ciudadana y formación de nuevos imaginarios culturales que reconozcan las diferencias y potencialidades de cada individuo.

Por otro lado, y en relación con el arte, Roca y Suárez (2012) plantean que el arte en Colombia durante las últimas décadas ha sido principalmente político en respuesta al conflicto armado. A su vez el Centro de Memoria Histórica abre el museo virtual Oropéndola $a^{4}$ para agrupar propuestas artísticas relacionadas con la reconstrucción de la memoria colectiva y la verdad. En ese sentido, la prácticas artísticas en Colombia empiezan a tener un énfasis visible en procesos de intervención social, lo que invita por un lado a la revisión misma de la noción de arte, de comunidad y a renovar la construcción simbólica de un país.

En este contexto, el Laboratorio cuerpo y diversidad en el arte. Intercambios gestuales, reconoce las diferencias de cada grupo poblacional, sus condiciones de vida, la afectación frente al conflicto y potencia su capacidad de generar nuevas formas de interpretar y recrear el mundo. En este espacio formativo la creación artística potencia el encuentro, en el que la diversidad se manifiesta de maneras contundentes en nuestras realidades cotidianas.

\section{¿Cómo surge Intercambios Gestuales?}

Un laboratorio que te sitúa en la circunstancia de no ser el poseedor de conocimiento, que te exige lo que tienes: cuerpo, pensamiento y emoción, para alcanzar un escenario que no es el cotidiano pero que te habla de ti y de otro, con el que siempre haz de interactuar, diferente pero finalmente otro como tú. (Fabio Torres, 2014) $)^{5}$

En 2008 se creó el Colectivo Otro como una articulación de profesionales de las artes, la educación y el trabajo comunitario que propenden por la formación, la investigación y la puesta en práctica de procesos, acciones e intervenciones artísticas, educativas e investigativas que inciden en la transformación de las condiciones de exclusión que viven algunas personas.

\footnotetext{
4. Ver: http://museo.centrodememoriahistorica.gov.co/oropendola/

5. Participante Laboratorio 2014. Psicopedagogo, narrador oral, facilitador socio - educativo. Institución Educativa José Joaquín Casas. Chía, Colombia. Reflexión final del laboratorio (Septiembre 13 y 14, 2014).
} 
Sumamos experiencias desarrolladas con artistas y comunidades, para poner en práctica los discursos emergentes de inclusión desde la equidad, y fortalecer las capacidades artísticas de quienes se interesan en los cuerpos diferenciados.

El laboratorio ha tenido lugar en distintas ciudades y municipios de Colombia: Bogotá (2008), Tulúa (2010), Cali (2011), Tunja y Facatativá (2012-2013), Bojacá, Chía y Tunja (2014), y Villavicencio y Boyacá (2015). En 2011 realizamos Primera Fase de Reconocimiento de Experiencias en Arte y Discapacidad del País, para la Dirección de Poblaciones del Ministerio de Cultura en 2011.

Como Colectivo, hemos visto ideas muy arraigadas en nuestra sociedad. Se entiende la normalidad desde una concepción occidental y patriarcal, haciendo que consideremos a los hombres racionales blancos y a las mujeres longilíneas objetualizadas como el ideal humano. De esta manera, aquel que sea mestizo, amarillo, rojo, negro, alto, bajo, ancho o muy delgado, homosexual, transexual, libertario, irreverente, viejo, que se contonee demasiado o que sea muy sensible, hará parte de lo diferente.

Muchos programas han tratado de incluir lo diferente, sin darse cuenta que esta premisa abre más la distancia entre unos y otros. Consideramos al ser humano desde sus cualidades sensibles, racionales, estéticas y espacio - temporales; susceptible de mirarse a sí mismo a la distancia, de construirse y renovar relaciones con el mundo. Su cuerpo es construido social y culturalmente, lo que nos permite dar un giro cualitativo al término diferencia, pues ésta no supone un grupo de personas con alguna característica particular que se aleje de la normalidad, sino una condición ineludible de nuestra naturaleza. Por tanto uno de los primeros paradigmas que cuestionamos el laboratorio, es precisamente la normalidad.

Desde esta perspectiva la discapacidad no es una enfermedad o una forma de nombrar un rasgo distintivo del ser humano, es la interacción fallida entre el potencial individual y el medio donde interactúa el sujeto. Bajo este enfoque, el sujeto encuentra en el contexto las posibilidades para su participación, autogestión, libertad, disfrute de sus derechos y posibilidades de desarrollo de sus habilidades particulares.

Para generar trabajar con todas las personas asumimos el acoger (Pujolàs, 2006) como un momento de acción en el que se abren posibilidades para dialogar como iguales, buscando valorar las características de cada cual. En este punto la relación con lo diferente se amplía, "porque todos pueden aprender de los demás y todos pueden enseñar algo a los otros" (Pujolàs, 2006, p.11). 
BOCANEGRA, CASTILLO, GARZÓN \& ROMERO / Intercambios gestuales: cuerpo y diversidad en el arte. Reflexiones desde el proceso de un laboratorio de creación en Colombia.

\section{La propuesta actual}

El propósito del laboratorio es que los participantes apropien, discutan y reelaboren concepciones de cuerpo desde el arte, su entorno, la producción cultural y simbólica en relación con la condición de discapacidad y exploren las relaciones entre arte y educación desde una perspectiva en la que el acto creativo se asume como un acto educativo, con las tensiones que esto implica. Cada lugar en donde lo llevamos a cabo tiene sus particularidades puesto que se parte de las experiencias previas de los participantes, en las que influyen la geografía de la región, las prácticas culturales que realizan, la idiosincrasia y la conformación misma del grupo.

Las metodologías que han ido fundamentando el trabajo en el tiempo son construccionistas, experienciales, centradas en la creación, colaborativas y reflexivas. Aspectos que generan didácticas diferenciadas de acuerdo con los objetivos planteados y que se median entre nosotras como laboratoristas y los participantes.

Es así como nos proponemos fortalecer habilidades en formulación, diseño y puesta en marcha de proyectos de creación y educación artística para comunidades con discapacidad, en las que las obras artísticas resignifiquen la diferencia y su incidencia comunitaria a partir de registros de las experiencias que realizan los participantes mientras se lleva a cabo el laboratorio.

Este se desarrolla en tres o cuatro encuentros por región y cuenta con una exposición final de cierre. Los encuentros tienen una duración de dos días, ocho horas diarias. Cada día de trabajo inicia con un ejercicio de respiración y movimiento, de manera que al mejorar la capacidad de oxigenación, iniciamos el trabajo con una disposición afectiva hacia la experiencia que se propone.

Por otra parte está el estudio del movimiento pues a través de él podemos notar cómo se encuentran las capacidades perceptivas del cuerpo. Se exploran la flexibilidad, coordinación, ritmo y expresión. Se enfatiza el gesto como la primera manifestación artística del ser y a partir de allí surgen los siguientes momentos del Laboratorio.

Después de pasar por la respiración y el movimiento, se hace una inmersión en problemas artísticos como metáfora de los cuestionamientos frente a la diferencia, la comunidad, la educación, la vida en el territorio y al arte mismo. Estos ejercicios tienen una duración aproximada entre dos y tres horas, pues pasan por un proceso de sensación, cuestionamiento, acción, socialización y reflexión. Al finalizar cada día de trabajo se hace un diálogo conjunto para valorar lo sucedido.

Los problemas artísticos que proponemos se organizan en cinco núcleos: Cuerpo desde el territorio: relaciones espaciales, geográficas y simbólicas con el lugar que se habita; cuerpo hecho imagen: el cuerpo como lugar de las imágenes; cuerpo 
hecho objeto: la materia como canal, túnel, puente para relacionarse y comunicarse con el otro; cuerpo hecho palabra: narraciones, descripciones y memoria; y, cuerpos colectivos: vínculos afectivos, prácticas de cuidado y comunidad.

\section{Cuerpo desde el territorio}

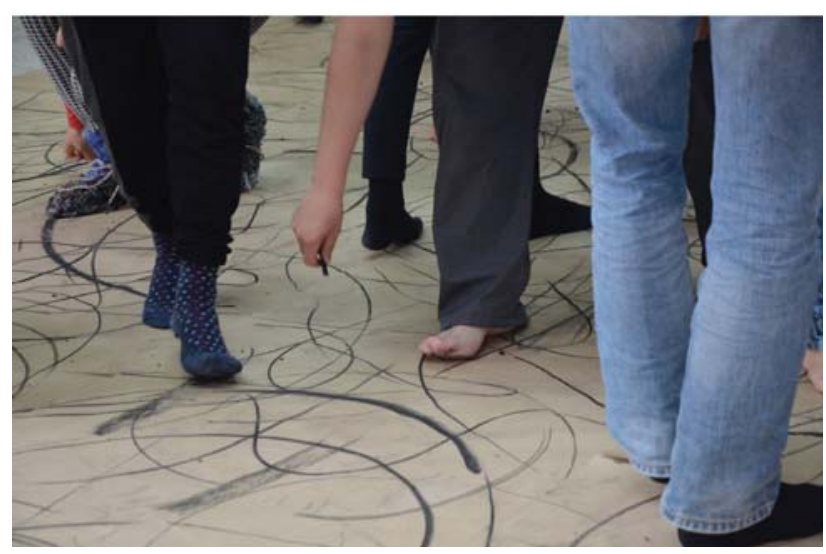

Figura 1. Colectivo Otro (2015). Ejercicio del territorio, Laboratorio Intercambios Gestuales. (Chía, Cundinamarca. Julio 2627) [fotografía/archivo particular]

Esta imagen muestra parcialmente un ejercicio que consistía en la creación de territorios individuales en un gran papel basados en el gesto gráfico. Cuando todos habían erigido su espacio, la tallerista irrumpía con pintura roja y daba la pauta de invadir el territorio del otro. Las personas comenzaban a rayar, arrancar y destrozar los lugares de los demás. Después de varios minutos de acciones sobre esta construcción colectiva se hacía un alto y se observaba lo sucedido. Los participantes pasaban por diversas emociones y llegaban a reflexiones sobre problemas y significaciones frente al territorio. Entre ellas la tenencia de la tierra y desplazamiento que se viven en Colombia por el conflicto armado, y las pequeñas invasiones al cuerpo del otro, a su territorio corporal y plástico. Luego se les retaba a construir un nuevo territorio común con los fragmentos que pudieran recuperar.

Lo anterior nos permite afirmar que pensar el cuerpo desde el territorio, requiere fijar la atención en las relaciones espaciales, geográficas y simbólicas con el lugar que se habita. El territorio se constituye por la acción cotidiana de una persona o un grupo sobre él. Si todos los días recorremos los mismos senderos, estos se transforman en la medida que son lugares de acontecimientos sociales. Quiere decir que, el territorio tiene particularidades geográficas particulares y a su vez las personas le otorgan características simbólicas de acuerdo a sus vivencias.

En relación con la discapacidad, nos preguntamos sobre el acceso, la posibilidad del disfrute, el intercambio y nuestra participación en la construcción conjunta de territorios. De aquí se deriva un asunto central: el cuerpo como territorio individual $y$ colectivo en el que se evidencian sus construcciones culturales. 
BOCANEGRA, CASTILLO, GARZÓN \& ROMERO / Intercambios gestuales: cuerpo y diversidad en el arte. Reflexiones desde el proceso de un laboratorio de creación en Colombia.

Desde nuestro territorio -"nuestro cuerpo"-, descubrimos conscientemente y reconocemos nuestra diversidad. Relacionamos lo que nos une y nos diferencia desde la sensibilidad, la percepción y las historias de vida, mediamos nuestra comunicación, salimos de nuestra propia comodidad para vincularnos, co-crear y habitarnos con el otro sin indiferencia ni negligencia. Nuestro cuerpo comunica nuestra condición humana con sus necesidades, y nos convoca a transformar la consciencia y comprensión de la vida, para aceptarnos y sernos. (Suander Llerolle, $2014)^{6}$

\section{Cuerpo hecho imagen}
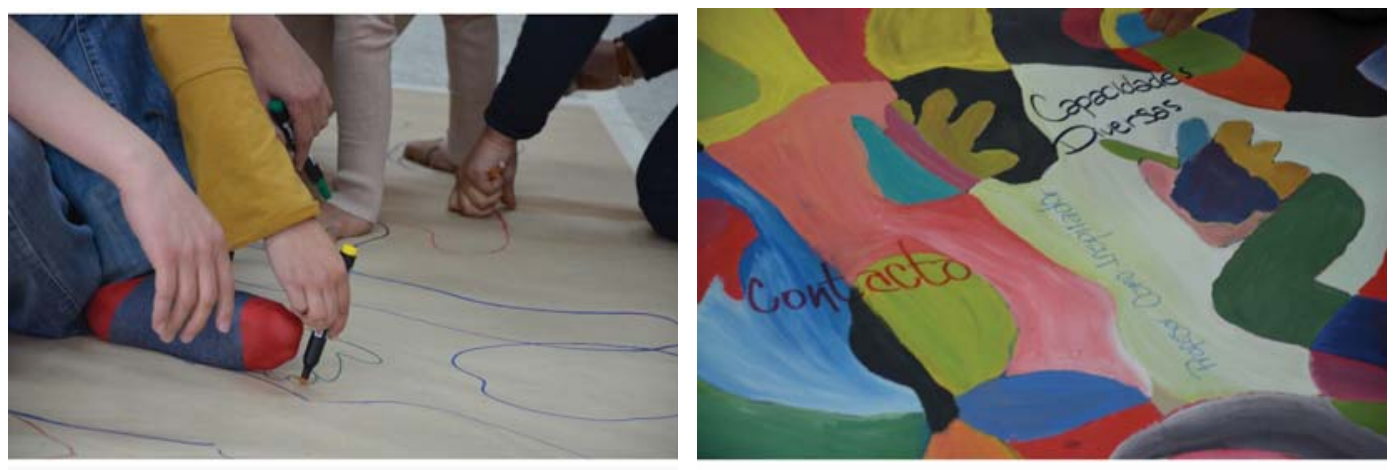

Figura 2. Colectivo Otro (2014). Cartografía corporal, Laboratorio Intercambios Gestuales, ChíaCundinamarca. [fotografia/archivo particular]

La imagen presenta un ejercicio que nace desde el cuerpo y que en relación con otros cuerpos ésta cambia de forma y materialidad. Los participantes se organizan en parejas, uno de ellos se acuesta en el piso y el otro traza su silueta. Cuando muchas huellas de cuerpos hayan sido puestas sobre el papel se llenan las intersecciones con los colores primarios y la mezcla entre ellos. Al finalizar la pintura, los cuerpos juntos pasan a ser una composición abstracta de color donde escriben los conceptos que atravesaron su experiencia.

Concebimos el cuerpo como el lugar de las imágenes ${ }^{7}$ y el lugar donde ellas cobran sentido y nos presentamos al mundo. Nuestra corporalidad, a través de sus gestos y movimientos, es imagen que nos habla de experiencias vividas, pensamientos y emociones.

En la discapacidad, el cuerpo hecho imagen es una posibilidad de expresión, creación y resignificación. Todos hemos estado en una etapa en la que llorar es el

6. Participante Laboratorio 2014. Artista formadora. Fundación Rafael Pombo. Chía, Colombia. Reflexión final del laboratorio (Septiembre 13 y 14, 2014).

7. Para ampliar la concepción del cuerpo como lugar de las imágenes consultar: Belting, H. (2007). Antropología de la Imagen. Madrid: Katz Editores. 
único camino por el que podemos manifestar nuestras emociones y deseos y hemos notado que son señales perceptibles, comprensibles para los demás. Entonces, buscamos ampliar la experiencia para que un diagnóstico pase a un segundo plano, y nos dispongamos a recorrer con el otro, a conocerlo, observarlo, escucharlo, a tratar de entenderlo, y permitirnos otras maneras de entrar en contacto. Partimos del reconocimiento de la corporalidad de cada participante, proponiendo ejercicios que vinculen la mente, el afecto y el cuerpo. Nos enfocamos en las cualidades del movimiento (niveles, velocidades, tamaños, extensiones, y direcciones), para ser conscientes de que desplazarse de un lugar a otro implica relaciones consigo mismo, con los objetos y los otros.

El sentido de la construcción por medio de uniones o amarres dio soporte de equilibrio para edificar y desarrollar ideas, donde la interacción humana es la acción relevante.

Hubo una relación y una motivación desde el movimiento corporal en cuanto nos vimos en la necesidad de realizar diversas posiciones hasta llegar a entrelazar sus cuerpos para sostener las construcciones que fuimos creando. (Virginia Niño, $2014)^{8}$

\section{Cuerpo hecho objeto}
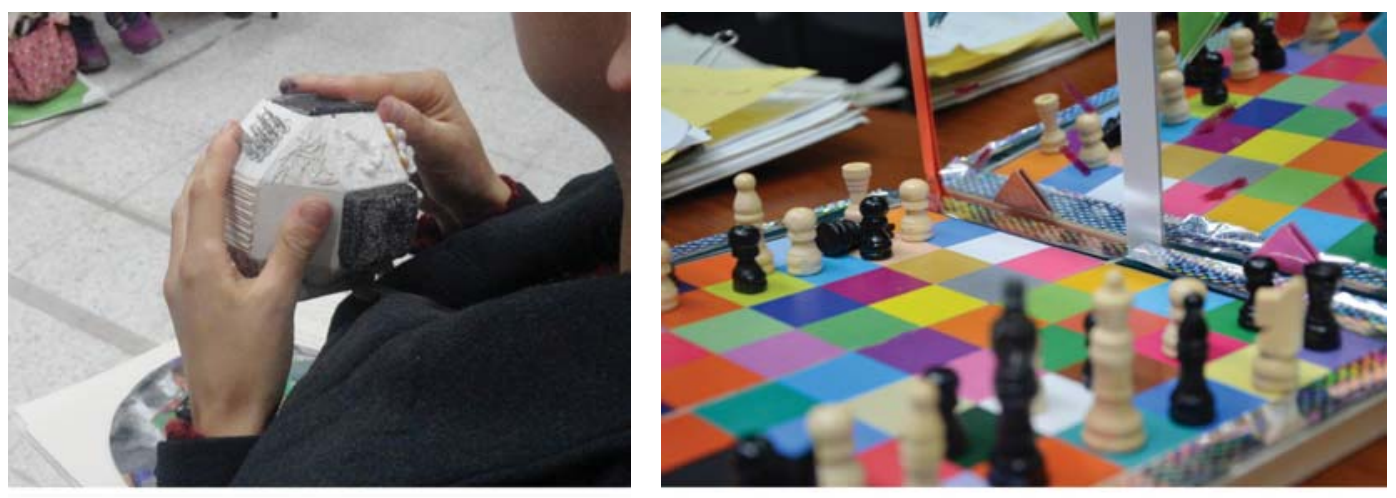

Figura 3. Colectivo Otro (2014). Centrarse en el objeto, Laboratorio Intercambios Gestuales, ChíaCundinamarca. [fotografía/archivo particular]

Este es un ejercicio de creación individual en la que los participantes buscan pensar y proyectar los objetos desde la afectación del cuerpo y del entorno, volviéndose éstos puentes de contacto con el mundo sensible e inmaterial del otro. Los objetos mediadores, son entendidos como posibilitadores del dialogo y del intercambio de experiencias entre los sujetos. Se diseñaron objetos para la experiencia sensible con texturas y colores, otros para el movimiento y la comunicación, algunos para la interacción con uno mismo.

8. Participante Laboratorio 2014. Maestra en artes plásticas y artista formadora. Casa de la Cultura de Chía. Chía, Colombia. Reflexión final del laboratorio (Septiembre 13 y 14, 2014). 
Por un lado, los procesos de creación que aquí se configuran, vinculan objetos y materiales para su materialización, pues estos actúan como detonantes para la relación con otro que implica comunicarse. Por otra parte, los objetos que se escapan al mundo del arte, y que nos resultan familiares, también cargas simbólicas culturales.

En el primer caso, los participantes ven en el objeto final el reflejo de una individualidad que en la discapacidad, muchas veces está oculta. Situaciones que pueden desencadenar dependencias vitalicias para comer, bañarse, desplazarse, vestirse, entre otras, hacen que el sujeto se despersonalice, pierda responsabilidad sobre sí mismo y olvide su capacidad de autogestión. En ese sentido, el arte le permite al sujeto renovar su autoimagen y comprender que la dependencia es dinámica y no necesariamente condenatoria.

En el segundo caso, nos olvidamos que los objetos están al servicio de los seres humanos y no al revés, por lo que acostumbrados al único pincel o cepillo de dientes que hay, afirmamos que la persona con discapacidad motora no puede pintar o asearse, cuando el problema radica en que el instrumento no es útil para aquella función corporal. Algunas parálisis cerebrales espásticas permiten solo ciertos movimientos corporales restringidos, lo que significa retos por ejemplo para los diseñadores industriales. Proponemos entonces, ejercicios en los que el objeto son del cuerpo que amplían capacidades y posibilidades; objetos que narran y significan. Los ejercicios están orientados al diseño y construcción de un objeto que permita generar una relación; esta búsqueda requiere espacios de prueba y error, que a su vez son gestionados por los participantes es sus espacios de trabajo. A partir del reconocimiento de nuestro cuerpo como territorio de construcción de conocimiento, generamos experiencias en las que los objetos cotidianos establecen un vínculo con el otro.

De este modo el objeto pasa a ser mediador o detonante de experiencias para contestar preguntas como: ¿Puedo establecer un vínculo con otra persona que no puede verme, oírme, o que se mueve de formas a las que no estoy acostumbrado? ¿Cómo acercarme a ese otro que no soporta la cercanía de mi cuerpo? ¿Cómo permito que la persona con discapacidad se sienta responsable de sus propias acciones sensibles?

Los objetos relacionales pueden ser vistos como mediadores de comportamientos colectivos que permiten llegar a un resultado o situación, a través de las prácticas que en torno a éstos se realizan. Es interesante ver como no solo incluyen un saber o capacidad individual si no que al transcurrir las diferentes situaciones que generan, afloran otros saberes como el afectivo, reflejados en actitudes o comportamientos en torno a la actividad en desarrollo. Estos saberes colaboran en la construcción de una inteligencia colectiva que busca obtener un fin, sea este hacer una composición, 
generar sonidos, o cumplir con una actividad específica, como cruzar de un lado a otro. (Andrés Castro, 2014) ${ }^{9}$

\section{Cuerpo hecho palabra}
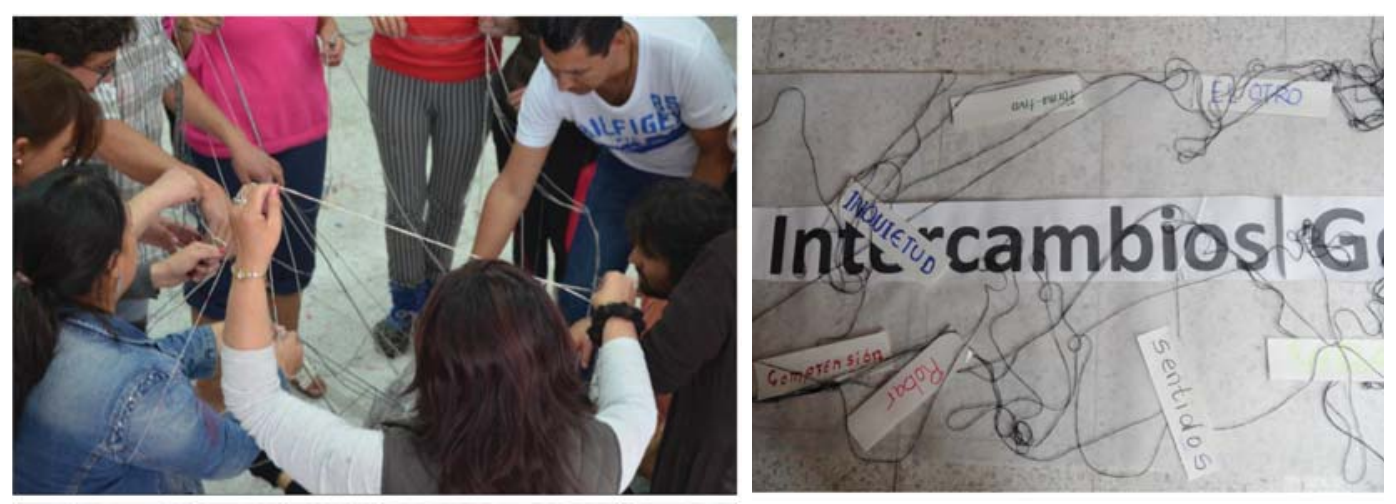

Figura 4. Colectivo Otro (2014). Red de saberes, Laboratorio Intercambios Gestuales, ChíaCundinamarca. [Fotografía/archivo particular]

A partir del nombre del laboratorio se visualizan los saberes de los participantes por medio en un juego performativo (tejer, unir y construir de manera colectiva). El hilo media para crear la metáfora de la palabra que se comparte y que se ata a un saber de otra persona, entrelazando así un proyecto compartido.

Hemos heredado la tradición de la narración oral, ahora considerada patrimonio inmaterial. En el Laboratorio, la palabra también es corporal, es materia de creación artística y a través de ella, experimentamos nombrarnos distinto a como ya sabíamos hacerlo. En uno de los laboratorios con madres comunitarias y cuidadoras en Bojacá, nos pidieron que habláramos de capacidades diversas para referirnos a la discapacidad, pues consideran que dicha expresión abarca mejor el sentido y el afecto con el que ellos acogen a cada miembro de su comunidad.

La palabra también permitió recrear historias, ligar conceptos, abrir preguntas e imaginar nuevas formas de concebir la realidad, nominarla distinto.

Hablar con el cuerpo en un lenguaje artístico es aprender a no codificar sino a entender cómo nos complementamos desde lo diverso. Es cubrir las carencias de unos con las generosidades de otros, las fragilidades con valentías, la ignorancia con experiencias y el talento con las emociones y las ganas de hacerlo. Es entender

9. Participante Laboratorio 2014. Diseñador Industrial y docente. Institución Educativa Diversificada de Chía. Chía, Colombia. Reflexión final del laboratorio (Septiembre 13 y 14, 2014). 
BOCANEGRA, CASTILLO, GARZÓN \& ROMERO / Intercambios gestuales: cuerpo y diversidad en el arte. Reflexiones desde el proceso de un laboratorio de creación en Colombia.

que el discurso que emana del pensamiento muchas veces no habla de lo que en esencia eres y se queda corto porque no sólo somos pensamiento. (Fabio Torres, 2014 $)^{10}$

\section{Cuerpos colectivos}
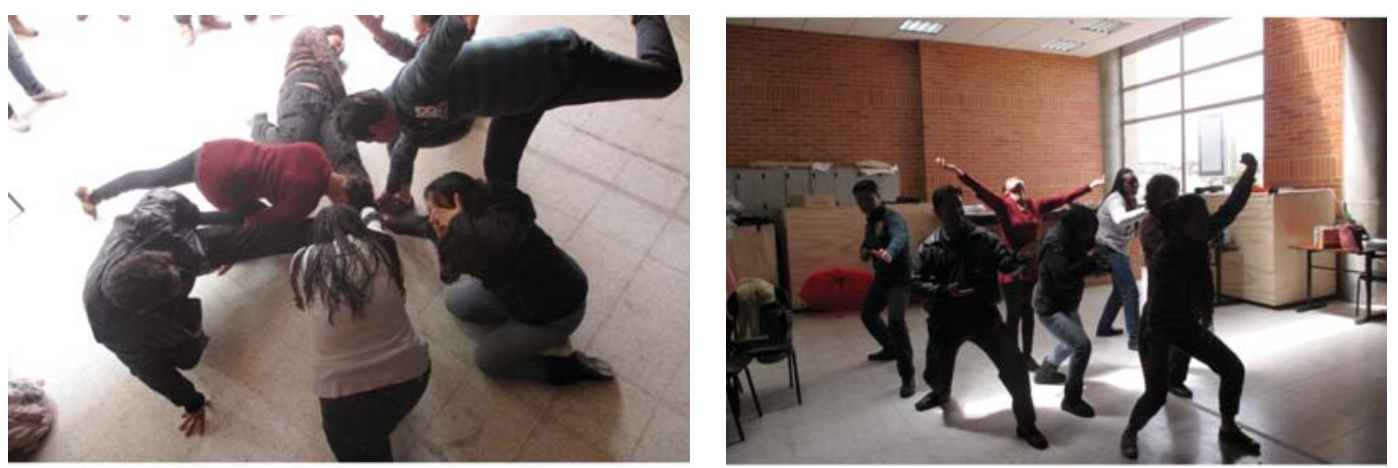

Figura 5. Colectivo Otro (2014). Esculturas corporales, Laboratorio Intercambios Gestuales, ChíaCundinamarca. [Fotografía/archivo particular]

El trabajo aquí realizado, se fundamenta a partir del teatro del oprimido de Augusto Boal. Se propone a los participantes crear una unidad simbólica de manera colectiva en la que se puedan trabajar imaginarios sociales con relación al poder, a la exclusión, a la diversidad, y al cuidado. Cada participante es un engranaje en esta construcción colectiva.

El cuerpo como imagen o unidad simbólica, no es una construcción puramente individual. La sociedad ejerce diversas fuerzas sobre los sujetos para determinar su imagen y forma, de manera que el cuerpo colectivo constituye aquella idea generalizada que vive en cada una de las personas. El laboratorio busca cuestionar el cuerpo colectivo bajo dos lentes: las prácticas de cuidado y las prácticas pedagógicas en relación al arte.

Las prácticas de cuidado y el afecto son conceptos presentes en la discapacidad, pues generan entre el cuidador y la persona relaciones de intimidad, confianza, cariño, agradecimiento e incluso deuda. Para que estas relaciones sean constructivas ponemos en juego la interdependencia, todos recibimos, ofrecemos reconocemos el valor de la interacción social para la construcción del tejido cultural y de la vida personal. Buscamos que cada participante sea consciente de su aporte a la comunidad a la vez que reflexiona sobre lo que para él significa vivenciar la diversidad en el otro.

11. Participante Laboratorio 2014. Psicopedagogo, narrador oral, facilitador socio - educativo. Institución Educativa José Joaquín Casas. Chía, Colombia. Reflexión final del laboratorio (Septiembre 13 y 14, 2014). 
Las prácticas pedagógicas también generan cuerpos colectivos. Sobrevaloramos la capacidad cognitiva del ser humano dejando de lado la potencialidad sensible, corpórea, estética, espiritual o afectiva de una persona; solemos preocuparnos mucho porque la persona con discapacidad cognitiva lea, cuente, sume, una puntos, iguale formas, maneje el espacio del renglón, memorice. Una educación centrada en las artes, amplía ese cuerpo colectivo. Entre más divergencias existan, las experiencias artísticas se potenciarán y los desafíos pedagógicos que esto implica se harán presentes. A partir de la experiencia artística reconocemos al otro en sus potencialidades y diferencias como parte importante de un grupo, capaz de aportar a la transformación simbólica de la comunidad de la que hace parte.

Intercambios Gestuales es un espacio de redes, de espejos, donde se escuchan con frecuencia expresiones como dejarse afectar, abrirse al otro, construir experiencias, compartir, dejar, despojarse o reconocer.

Esta propuesta de encuentros vivenciales y actividades personales con y desde el arte y la pedagogía para integrar la diversidad ha sido una ocasión para expresar y recibir, mostrar y observar, producir y escuchar, ofrecer y permitir, compartir y conocer, entre otras muchas cosas. (Sandra Álvarez, 2014) ${ }^{11}$

\section{En perspectiva de investigación}

Dentro del proceso de laboratorio hemos insistido en los procesos de documentación y registro, con el objeto de configurar materiales para la investigación desde las propias prácticas que cada quien adelanta.

11. Participante Laboratorio 2014. Licenciada en Preescolar. Institución Educativa Fagua. Chía, Colombia. Reflexión final del laboratorio (Septiembre 13 y 14, 2014). 


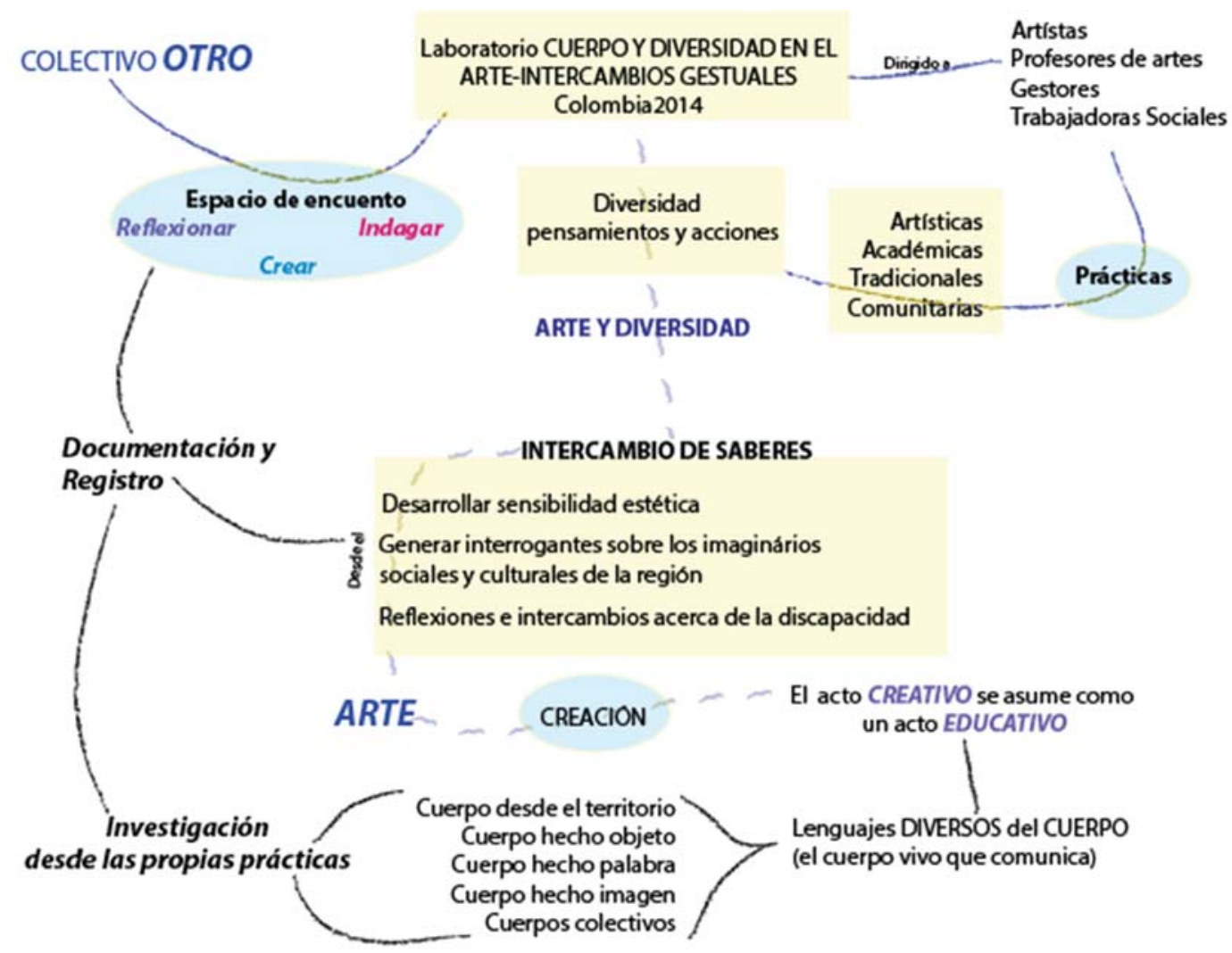

Figura 6. Colectivo Otro (2015). Mapa de navegación del laboratorio, construcción colaboractiva. [Diagrama/archivo particular]

Esto quiere decir que mientras se investiga, se participa y quienes deciden hacerlo se transforman (Ander-Egg, 2003) a través de acciones artísticas con interés pedagógico. El oficio del artista - profesor es participar creativa y críticamente en estos procesos, para que esto sea posible la sensibilidad del docente es fundamental en una primera apuesta que confronte su imaginario en relación con la discapacidad.

De este modo se comparte la experiencia de cada participante para la formación de un saber nacional sobre la discapacidad en el campo de las artes y la educación desde prácticas concretas, situadas, encarnadas. Es así como se crean comunidades de aprendizaje desde las artes, que valoran sus propias prácticas y que están en constante construcción de una sociedad más justa en oportunidades para todos sus habitantes.

La experiencia vital es el insumo de la creación, por lo que promover experiencias estéticas de autodescubrimiento es fructífero para el desarrollo colectivo, invita a los participantes a permear en su singularidad y la forma a través de la cual se relacionan con el mundo, los motiva a indagarse.

A pesar de que somos multidimensionales, se requiere de voluntad y ejercicio para llegar a la integralidad en la experiencia en la que el cuerpo, la afectividad y la conciencia trabajen de forma coordinada y consecuente. Actualmente, el interés por 
el cuerpo ha trascendido las disciplinas. Éste central para ponerse en relación con otros. (Brigeiro, 2005), lo que nos sitúa en un campo de conocimientos expandidos.

Con relación al arte, éste no solo es una acción contemplativa sino dinámica. Trata al cuerpo como materia plástica en la que se mantiene cierto grado de la indeterminación. La exploración del cuerpo como materia sensible y pensante, nos sitúa ante los otros, decodificamos códigos corporales, apropiamos algunos y nos desplazamos entre ellos; de manera que en la percepción corporal también se hallan canales de comunicación distintos al lenguaje verbal o escrito.

La mirada atenta, el cuidado de sí mismo y el otro, la manifestación y la elaboración creativa de las emociones, nos permite integrar en una acción la experiencia humana, preparándonos para el convivir con solidaridad, respeto y empatía. De esta manera el sentido de la discapacidad se transforma y la diversidad será aquello que define y condensa lo que nos caracteriza como especie. De esta manera los haceres, sentires y pensares (Csikszentmihalyi, 2007), expresan la necesidad de una integración multidimensional en las acciones que trabajadas de manera conjunta construyen y erigen comunidad.

\section{Conclusiones}

Como colectivo de artistas que hace parte de un Programa Nacional de Laboratorios de Creación en Artes visuales en Colombia, nos cuestionamos constantemente sobre los tránsitos entre el ámbito pedagógico, y la investigación y creación artística relacionada con diversidad y en contextos comunitarios específicos.

Buscamos dialogar, reelaborar y discutir, la imagen socialmente construida de la diversidad debatiendo lo que hacemos en el aula, en nuestras prácticas cotidianas, en la universidad, y en los territorios que habitamos.

Vemos en el cuerpo el lugar potente donde la experiencia y los saberes se concretan en el encuentro con otros cuerpos diferentes al propio.

En el espacio del Laboratorio confluyen tensiones entre la práctica artística y la práctica pedagógica, donde las relaciones dialógicas con los materiales, los cuerpos y los saberes permiten deconstruir el pensamiento, volverlo maleable y evaluar con frecuencia los procesos y los actores.

\section{Referencias bibliográficas}

Ander-Egg, E. (2003). Repensando la Investigación-Acción Participativa. Buenos Aires: Lumen Hvmanitas. 
BOCANEGRA, CASTILLO, GARZÓN \& ROMERO / Intercambios gestuales: cuerpo y diversidad en el arte. Reflexiones desde el proceso de un laboratorio de creación en Colombia.

Belting, H. (2007). Antropología de la Imagen. Madrid: Katz Editores.

Boal, A. (2002). Juegos para actores y no actores. Merlino, M. (trad). Barcelona: Alba Editorial S.I.U.

Brigeiro, M. (2005). Cuerpo, cultura y discapacidad: Aproximaciones analíticas desde la teoría social. Cuervo, C., Trujillo, A., Vargas, D., Mena, B., y Pérez, L. (eds.). En: Discapacidad e Inclusión Social: Reflexiones desde la Universidad Nacional de Colombia. Bogotá: Universidad Nacional de Colombia.

Chaparro-Amaya, A. (2005). Procesos de subjetivación, conflicto armado y construcción del Estado Nación en Colombia. En: Revista Estudios Socio-Jurídicos, 7, 411-469. Recuperado de: http://www.redalyc.org/articulo.oa?id=73309911

Csikszentmihalyi, M. (2007). Aprender a Fluir. Barcelona: Kairós.

Jaramillo, S. (2013). La paz territorial. Alto comisionado para la paz. Recuperado de: http://www.altocomisionadoparalapaz.gov.co/herramientas/discursos/Documents/ La_Paz_Territorial_version_final.pdf

Pujolàs, P. (2006). Aulas inclusivas y aprendizaje cooperativo. Recuperado de: http://www.unizar.es/cce/atencion_diversidad/ap\%20cooper.pdf

Roca, J. y Suárez, S. (2012). Transpolítico, Arte en Colombia 2002-2012. Barcelona: Lunwerg Editores. 